\title{
Application of EDAS Method on Water Requirement in Agriculture
}

\author{
Dr. A. Sahaya Sudha \\ Assistant Professor, \\ Department of Mathematics \\ Nirmala College for Women, \\ Coimbatore, India
}

\begin{abstract}
Muticriteria Decision making is the latest developing mathematical technique which is being followed in management practices. Due to the complexity of a given situation the expected results are ambiguous and vague in the decision making process. This can be done by using the Mathematical analysis of a given situation by using one of the MCDM Methods called Evaluation based on Distance from Average solution (EDAS) method. In this paper an agricultural situation in a locality is considered where various parameters on water management in Agricultural crops are considered. So, to find a better alternative a study has been taken on different crops of different durations, water consumption, yield, market pricing and is mathematically evaluated by applying EDAS method for efficient water management practices for an agriculturist.
\end{abstract}

Keywords-MCDM, water Management, EDAS, crop selection, irrigation

\section{INTRODUCTION}

Multicriteria Decision making (MCDM) is a process of arriving at the best appropriate solution from a set of available alternatives in relation to a set of evaluation criteria. The MCDM methods have been discussed by various authors and has been published in a number of scientific and technical journals and proposed methods for solving various MCDM problems in areas of Economics[2,4], Management $[8,9]$,

production [10,11],sustainabledevelopment, [3,5],

construction, [3,13,14] Logistics, [12] to name a few. The Evaluation Based on Distance from Average Solution (EDAS) is a new and efficient MCDM method. This was proposed and further extended EDAS method for multi criteria Decision Making by Keshavarz Ghorabaee et.al., $[1,6,7]$. The desirability of alternatives in this method is determined based on distances of them from an average solution (AV). Here we have two measures of dealing with the desirability of the alternatives. The first measure is the positive distance from average (PDA), and the second is the negative distance from average (NDA). These measures shows the difference between each solution (alternative) and the average solution. The evaluation of the alternatives is made according to higher values of PDA and lower values of NDA. Higher values of PDA and/or lower values of NDA represent that the solution (alternative) is better than average solution.

\section{MATHEMATICAL ALGORITHM FOR THE PROPOSED METHOD}

The Mathematical procedure for the EDAS method for a decision making problem with $\mathrm{n}$ criteria and $\mathrm{m}$ alternatives can analyzed as per the following procedures:

Step: 1 Select the available alternatives and the most important criteria which describes the alternatives to construct a Decision Making Matrix D as:

$$
\begin{aligned}
& \begin{array}{lllll}
\mathrm{C}_{1} & \mathrm{C}_{2} & \mathrm{C}_{3} & \ldots & \mathrm{C}_{\mathrm{n}}
\end{array} \\
& \mathrm{D}=\begin{array}{c}
\mathrm{A}_{1} \\
\mathrm{~A}_{2} \\
\mathrm{~A}_{3} \\
\cdot \\
\cdot \\
\cdot \\
\mathrm{A}_{m}
\end{array}\left[\begin{array}{ccccc}
\mathrm{X}_{11} & \mathrm{X}_{12} & \mathrm{X}_{13} & \ldots & \mathrm{X}_{1 \mathrm{n}} \\
\mathrm{X}_{21} & \mathrm{X}_{22} & \mathrm{X}_{23} & \cdots & \mathrm{X}_{2 \mathrm{n}} \\
\mathrm{X}_{31} & \mathrm{X}_{32} & \mathrm{X}_{33} & \cdots & \mathrm{X}_{3 \mathrm{n}} \\
\cdot & \cdot & \cdot & \cdot & \cdot \\
\cdot & \cdot & \cdot & \cdot & \cdot \\
\cdot & \cdot & \cdot & \cdot & \cdot \\
\mathrm{X}_{\mathrm{m} 1} & \mathrm{X}_{\mathrm{m} 2} & \mathrm{X}_{\mathrm{m} 3} & \cdots & \mathrm{X}_{\mathrm{mn}}
\end{array}\right)
\end{aligned}
$$

Where $\mathrm{w}=\left[w_{1}, w_{2}, w_{3}, \ldots, \mathrm{w}_{\mathrm{n}}\right]$

Let $A_{1}, A_{2}, A_{3}, \ldots, A_{m}$ are possible alternatives among which decision makers have to choose $C_{1}, C_{2}, C_{3}, \ldots, C_{n}$ are criteria with which alternatives performance are measured, $x_{i j}$ is the performance value of alternatives $A_{i}$ with respect to criterion $C_{j}, w_{j}$ is the weight of criterion $C_{j}$ and all $\mathrm{x}_{\mathrm{ij}}$ are positive numbers

Step 2: Determine the average solution $(A V j)$ according to all the criteria as per the formula:

$$
A V_{j}=\frac{\sum_{i=1}^{n} x_{i j}}{n}
$$

Step 3: The Positive Distance from average (PDA) is calculated according to the criteria which are beneficial or non

beneficial:

$$
\begin{aligned}
& \text { If } j^{\text {th }} \text { criterion is beneficial } \\
& P D A_{i j}=\frac{\left.\max \left(0,\left(X_{i j}-A V_{i j}\right)\right)\right)}{A V_{j}} \\
& \text { If } j^{\text {th }} \text { criterion is non }- \text { beneficial } \\
& P D A_{i j}=\frac{\max \left(0,\left(A V_{j}-X_{i j}\right)\right)}{A V_{j}}
\end{aligned}
$$


Step 4: Calculate the Negative Distance from average (NDA) is calculated according to the criteria

$$
\begin{aligned}
& \text { If } j^{\text {th }} \text { criterion is beneficial } \\
& N D A_{i j}=\frac{\left.\max \left(0, A V_{j}-X_{i j}\right)\right)}{A V_{j}} \\
& \text { If } j^{\text {th }} \text { criterion is non }- \text { beneficial } \\
& N D A_{i j}=\frac{\left.\max \left(0,\left(X_{i j}-A V_{i j}\right)\right)\right)}{A V_{j}} .
\end{aligned}
$$

Step 5: The Weighted sum of PDA is obtained from the Average Matrix:

$$
S P_{i}=\sum_{j=1}^{m} w_{j} P D A_{i j}
$$

where $w_{j}$ denotes the weight of the criteria $j$

Step 6: The Weighted sum of NDA is obtained from the Average Matrix:

$$
S N_{i}=\sum_{j=1}^{m} w_{j} N D A_{i j}
$$

Step 7 : The Normalized values of $\mathrm{SP}_{\mathrm{i}}$ and $\mathrm{SN}_{\mathrm{i}}$ for all alternatives is calculated as follows:

$$
\begin{aligned}
N S P_{i} & =\frac{S P_{i}}{\max _{i}\left(S P_{i}\right)} \\
N S N_{i} & =1-\frac{S N_{i}}{\max _{i}\left(S N_{i}\right)}
\end{aligned}
$$

Where $\mathrm{NSP}_{\mathrm{i}}$ and $\mathrm{NSN}_{\mathrm{i}}$ denote the normalized weighted sum of PDA and NDA respectively

Step 8: The appraisal score $\mathrm{AS}_{\mathrm{i}}$ for all alternatives is obtained as:

$$
A S_{i}=\frac{1}{2}\left(N S P_{i}+N S N_{i}\right)
$$

\section{where $0 \leq A S_{i} \leq 1$}

Step 9: The alternatives are ranked according to the decreasing values of appraisal score $\left(\mathrm{AS}_{\mathrm{i}}\right)$. The alternative with the highest $A S_{i}$ is the best choice among the alternatives.

\section{CASE ANALYSIS}

In this paper a decision making approach with an example of an agricultural activity is considered. An analysis of crops of different durations and different water requirement along with the production of economies is considered in a farming activity in a particular locality. A data pertaining to nine different types of crops based on their duration along with Income, Water Cost and the Quantity of water required using both Drip and Flood Irrigation methods is calculated as per the cropping pattern. According to the farmers requirement 9 assigned alternatives $\mathrm{A}_{1}, \mathrm{~A}_{2}, \mathrm{~A}_{3}, \mathrm{~A}_{4}, \mathrm{~A}_{5}, \mathrm{~A}_{6}, \mathrm{~A}_{7}, \mathrm{~A}_{8}, \mathrm{~A}_{9}$ are selected where the alternatives $A_{1}, A_{2} \&, A_{3}$ are Long duration crops of 300-360 days, $\mathrm{A}_{4}, \mathrm{~A}_{5}, \& \mathrm{~A}_{6}$ are medium duration crops of 120 -140 days and $A_{7}, A_{8}, \& A_{9}$ are short duration crops from 60-90 days. Here the economics of scale are worked out by giving the best option for a farmer to decide and cultivate a crop which is best suited along with the availability of resources where the main emphasis is on water conservation. Since water is the main source for agriculture we have considered the main criteria as water requirement in this paper. The Criteria $\mathrm{C}_{1}, \mathrm{C}_{2}$ and $\mathrm{C}_{3}$ are Income, Water Consumption and Water Cost .The above criteria is arrived based on the availability and usage of water for a given crop and also the cost of water are worked out based on the yield and market price. It may also be noted that the other cost of inputs are not taken here since this is not significant in this study even though the other factors also influence the Economics of Farming activity.

TABLE I

CRITERIA DESCRIPTION

\begin{tabular}{|l|l|}
\hline Criteria & Description \\
\hline Income & Income obtained from crop cultivation \\
\hline Water consumption & Quantity of Water required for the crop \\
\hline Water Cost & $\begin{array}{l}\text { Cost involved in the water usage in crop } \\
\text { cultivation }\end{array}$ \\
\hline
\end{tabular}

TABLE II

DECISION MATRIX- DRIP IRRIGATION

\begin{tabular}{|c|c|c|c|}
\hline \multicolumn{5}{|c|}{ Criteria } \\
\hline Alternatives & Income(C) & $\begin{array}{l}\text { Water } \\
\text { Consumption }\left(\mathbf{C}_{\mathbf{2}}\right)\end{array}$ & $\begin{array}{l}\text { Water } \\
\text { Cost }\left(\mathbf{C}_{\mathbf{3}}\right)\end{array}$ \\
\hline $\mathbf{A}_{\mathbf{1}}$ & 188.57 & 13.71 & 0.07 \\
\hline $\mathbf{A}_{\mathbf{2}}$ & 4165.00 & 18.33 & 0.00 \\
\hline $\mathbf{A}_{\mathbf{3}}$ & 1894.23 & 23.08 & 0.01 \\
\hline $\mathbf{A}_{\mathbf{4}}$ & 489.09 & 15.15 & 0.03 \\
\hline $\mathbf{A}_{\mathbf{5}}$ & 188.57 & 11.43 & 0.06 \\
\hline $\mathbf{A}_{\mathbf{6}}$ & 1087.50 & 14.58 & 0.01 \\
\hline $\mathbf{A}_{\mathbf{7}}$ & 261.67 & 27.50 & 0.11 \\
\hline $\mathbf{A}_{\mathbf{8}}$ & 858.89 & 14.44 & 0.02 \\
\hline $\mathbf{A}_{\mathbf{9}}$ & 850.00 & 33.33 & 0.04 \\
\hline
\end{tabular}

TABLE III

DECISION MATRIX - FLOOD IRRIGATION

\begin{tabular}{|c|c|c|c|}
\hline \multicolumn{4}{|c|}{ Criteria } \\
\hline Alternative & Income(C) & $\begin{array}{l}\text { Water } \\
\text { Consumption }\left(\mathbf{C}_{\mathbf{2}}\right)\end{array}$ & $\begin{array}{l}\text { Water } \\
\text { Cost }\left(\mathbf{C}_{\mathbf{3}}\right)\end{array}$ \\
\hline $\mathbf{A}_{\mathbf{1}}$ & 111.43 & 20.00 & 0.18 \\
\hline $\mathbf{A}_{\mathbf{2}}$ & 1726.67 & 26.67 & 0.02 \\
\hline $\mathbf{A}_{\mathbf{3}}$ & 1807.69 & 36.54 & 0.02 \\
\hline $\mathbf{A}_{\mathbf{4}}$ & 429.09 & 19.39 & 0.05 \\
\hline $\mathbf{A}_{\mathbf{5}}$ & 111.43 & 17.86 & 0.16 \\
\hline $\mathbf{A}_{\mathbf{6}}$ & 975.00 & 23.33 & 0.02 \\
\hline $\mathbf{A}_{\mathbf{7}}$ & 171.67 & 30.00 & 0.17 \\
\hline $\mathbf{A}_{\mathbf{8}}$ & 768.89 & 23.33 & 0.03 \\
\hline $\mathbf{A}_{\mathbf{9}}$ & 775.00 & 50.00 & 0.06 \\
\hline
\end{tabular}

Step 1: The average solution for Drip Irrigation is calculated from the Table 2

$$
\begin{aligned}
& \left(A V_{j}\right)\left(C_{1}\right)=\frac{9983.28}{9}=1109.28,\left(\mathrm{AV}_{\mathrm{j}}\right)\left(\mathrm{C}_{2}\right)=19.06 \\
& \left(\mathrm{AV}_{\mathrm{j}}\right)\left(\mathrm{C}_{3}\right)=0.038
\end{aligned}
$$

The average solution for Flood Irrigation is calculated from the Table III

$$
\left(A V_{j}\right)\left(C_{1}\right)=764.10,\left(A V_{j}\right)\left(C_{2}\right)=27.46, \quad(A V j)\left(C_{3}\right)=0.08
$$


Step2: The Positive distance from average (PDA) for Drip Irrigation is

$$
\begin{aligned}
& P_{11}\left(C_{11}\right)=\frac{\max \left(0,\left(\mathrm{x}_{11}-A V_{j}\left(c_{1}\right)\right)\right.}{A v_{j}\left(C_{1}\right)}=\frac{\max (0,0-1109.28)}{1109.28}=0.0000 \\
& P D A_{12}\left(C_{12}\right)=\frac{\max \left(0,\left(A V_{j}\left(c_{2}\right)-X_{12}\right)\right)}{A v_{j}\left(C_{2}\right)}=\frac{\max (0,(19.06-13.71)}{19.06}=0.2806
\end{aligned}
$$

Similarly other values for Positive distance from average (PDA) for Drip Irrigation is calculated

Step: 3 The Negative Distance from average (NDA) for Drip Irrigation is

$$
N D A_{11}\left(C_{11}\right)=\frac{\max \left(0,\left(A V_{j}\left(c_{1}\right)-X_{12}\right)\right)}{A v_{j}\left(C_{2}\right)}=\frac{\max (0,(1109.28-188.57))}{1109.28}=0.8300
$$$$
N D A_{12}\left(C_{12}\right)=\frac{\max \left(0,\left(\mathrm{x}_{12}-A V_{j}\left(c_{1}\right)\right)\right.}{A v_{j}\left(C_{1}\right)}=\frac{\max (0,(13.71-19.06))}{19.06}=0
$$

Similarly the other values also calculated

Step: 4 Weighted sum of PDA is calculated by multiplying the weights of each value in Step 2

$$
\text { where } \mathrm{w}_{1}=0.33, \mathrm{w}_{2}=0.33, \mathrm{w}_{3}=0.33
$$

Step: 5 Weighted sum of NDA $\left(\mathrm{SN}_{\mathrm{i}}\right)$ ) is calculated by multiplying the weights of each value in Step 3 where $\mathrm{w}_{1}=0.33, \mathrm{w}_{2}=0.33, \mathrm{w}_{3}=0.33$

Step: 6 The following table shows the Normalized values of $\mathrm{SP}_{\mathrm{i}}, \mathrm{SN}_{\mathrm{i}}$ and the Appraisal score $\left(\mathrm{AS}_{\mathrm{i}}\right)$ is obtained using the Formula given in the Step7and step8 of Algorithm

TABLE IV

NORMALIZED VALUES OF $\mathrm{SP}_{\mathrm{I}} \& \mathrm{SN}_{\mathrm{I}}-$ DRIP IRRIGATION

\begin{tabular}{|l|l|l|l|l|l|l|}
\hline Alternatives & $\mathbf{S P i}$ & $\mathbf{S N i}$ & $\mathbf{N S P i}$ & $\mathbf{N S N i}$ & $\mathbf{A S}_{\mathbf{i}}$ & Ranking \\
\hline $\mathbf{A}_{\mathbf{1}}$ & 0.0926 & 0.5516 & 0.0762 & 0.4171 & 0.2467 & $\mathbf{7}$ \\
\hline $\mathbf{A}_{\mathbf{2}}$ & 1.2149 & 0.0000 & 1.0000 & 1.0000 & 1.0000 & $\mathbf{8}$ \\
\hline $\mathbf{A}_{\mathbf{3}}$ & 0.4617 & 0.0695 & 0.3800 & 0.9266 & 0.6533 & $\mathbf{1}$ \\
\hline $\mathbf{A}_{\mathbf{4}}$ & 0.1389 & 0.1845 & 0.1143 & 0.8050 & 0.4597 & $\mathbf{4}$ \\
\hline $\mathbf{A}_{\mathbf{5}}$ & 0.1322 & 0.4503 & 0.1088 & 0.5242 & 0.3165 & $\mathbf{6}$ \\
\hline $\mathbf{A}_{\mathbf{6}}$ & 0.2955 & 0.0065 & 0.2432 & 0.9932 & 0.6182 & $\mathbf{2}$ \\
\hline $\mathbf{A}_{\mathbf{7}}$ & 0.0000 & 0.9464 & 0.0000 & 0.0000 & 0.0000 & $\mathbf{9}$ \\
\hline $\mathbf{A}_{\mathbf{8}}$ & 0.2694 & 0.0745 & 0.2218 & 0.9213 & 0.5715 & $\mathbf{3}$ \\
\hline $\mathbf{A}_{\mathbf{9}}$ & 0.0023 & 0.3242 & 0.0019 & 0.6575 & 0.3297 & $\mathbf{5}$ \\
\hline
\end{tabular}

Similarly we can calculate the values for Flood Irrigation also and the values are obtained in Table 5
TABLE V

RANKING OF FLOOD IRRIGATION

\begin{tabular}{|l|l|l|l|l|l|l|}
\hline Alternatives & $\mathbf{S P i}$ & $\mathbf{S N i}$ & $\mathbf{N S P i}$ & $\mathbf{N S N i}$ & $\mathbf{A S i}$ & Ranking \\
\hline $\mathbf{A}_{\mathbf{1}}$ & 0.0896 & 0.6983 & 0.1287 & 0.0000 & 0.0643 & $\mathbf{8}$ \\
\hline $\mathbf{A}_{\mathbf{2}}$ & 0.6910 & 0.0000 & 0.9919 & 1.0000 & 0.9959 & $\mathbf{1}$ \\
\hline $\mathbf{A}_{\mathbf{3}}$ & 0.6967 & 0.1091 & 1.0000 & 0.8437 & 0.9219 & $\mathbf{2}$ \\
\hline $\mathbf{A}_{\mathbf{4}}$ & 0.2389 & 0.1447 & 0.3430 & 0.7928 & 0.5679 & $\mathbf{5}$ \\
\hline $\mathbf{A}_{\mathbf{5}}$ & 0.1154 & 0.6183 & 0.1656 & 0.1145 & 0.1401 & $\mathbf{7}$ \\
\hline $\mathbf{A}_{\mathbf{6}}$ & 0.3711 & 0.0000 & 0.5327 & 1.0000 & 0.7664 & $\mathbf{3}$ \\
\hline $\mathbf{A}_{\mathbf{7}}$ & 0.0000 & 0.6832 & 0.0000 & 0.0217 & 0.0108 & $\mathbf{9}$ \\
\hline $\mathbf{A}_{\mathbf{8}}$ & 0.2554 & 0.0000 & 0.3667 & 1.0000 & 0.6833 & $\mathbf{4}$ \\
\hline $\mathbf{A}_{\mathbf{9}}$ & 0.0664 & 0.2709 & 0.0953 & 0.6120 & 0.3537 & $\mathbf{6}$ \\
\hline
\end{tabular}

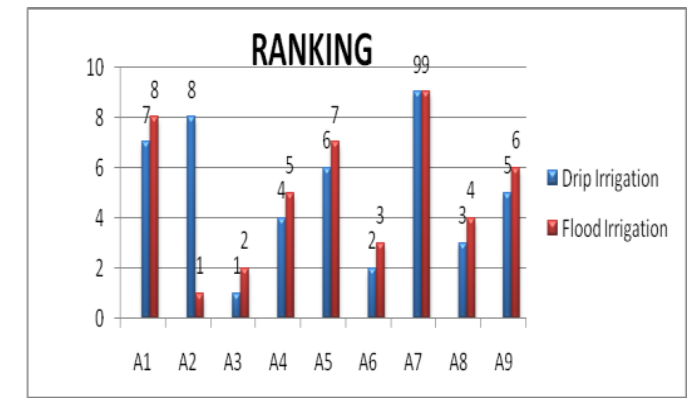

Fig 1: Pictorial Representation of Ranking - Drip \& Flood Irrigation

\section{CONCLUSIONS}

In this paper the EDAS method is applied to solve a multi criteria decision making problem of finding the best crop suited on the basis of minimum water requirement along with a higher income for a farmer. Here the best alternative of crop is suggested by considering lower cost and less usage of water with a higher income. The ranking of the alternatives for Drip Irrigation method in order are $A_{3}>A_{6}>A_{8}>A_{4}>A_{9}>A_{5}>$ $A_{1}>A_{2}>A_{7}$. Results indicate that $A_{3}$ is the best alternative with $A S_{i}$ value of 0.6533 .The ranking of the alternatives for Flood Irrigation in order are $A_{2}>A_{3}>A_{6}>A_{8}>A_{4}>A_{9}>A_{5}$ $>A_{1}>A_{7}$. Results indicate that $A_{2}$ is the best alternative with $\mathrm{AS}_{i}$ value of 0.9959 wherein $\mathrm{A}_{2}$ which is the best alternative in Flood Irrigation method. This method can be used to arrive at a decision for any number of crops also with number alternatives. Similarly this ranking also can be used for different durations based crops as per the above results, where Crop $A_{3}$ is suited in long duration, $A_{6}$ is suited in terms of medium duration and $A_{8}$ is suited for short duration in the case of Drip Irrigation .In case of Flood Irrigation the best crop is $A_{2}, A_{6}$ and $A_{8}$ for long duration, Medium duration and short duration crops respectively.

\section{REFERENCES}

[1] Amiri M, Keshavarz Ghorabaee M, Turskis Z, Zavadskas E.K 2016. "Extended EDAS method for fuzzy multi-criteria decision-making an application to supplier selection". International Journal of Computers Communications \&Control, 11(3): 358-371.

[2] Amiri M, Keshavarz Ghorabaee M, Turskis Z, Zavadskas E.K 2017., "Multi-criteria group decision-making using an extended EDAS method with interval type-2 Fuzzy sets", E\&M Ekonomie a Management,20(1): 48-68. 
[3] Cevik Onar S, Kahraman C, Keshavarz Ghorabaee M, Oztaysi B, Yazdani M,Zavadskas E.K.,2017 Intuitionistic fuzzy EDAS method: An application to olidwaste disposal site selection, Journal of Environmental Engineering and Landscape Management 25(1): 1-1.

[4] Ghadikolaei,A.S.,Esbouei,S.K.,Antucheviciene ,J 2014 "Applying fuzzy MCDM for financial performance evaluation of Iranian companies." Technological and Economic Development of Economy,20(2) :274-291

[5] Ghosh,S ,Chakraborthy,T ...Saha, S. Majumder,M., Pal,M 2016,.Development of the local suitability index for wave energy production by ANN and MCDM techniques .Renewable and Sustainable Energy Reviews 59:1017-1028.

[6] Keshavarz Ghorabaee M, Olfat L, Turskis Z, Zavadskas E.K., 2015,Multicriteria inventory classification using a new method of evaluation based on distance from average solution (EDAS). Informatica, 26(3): 435-451.

[7] Keshavarz Ghorabaee M, Stanujkic D, Turskis Z, Zavadskas E.K.,2017, An extension of the EDAS method based on the use of interval grey numbers, Studies in Informatics and Control 26(1):5-1

[8] Li, M., Jin, L., \&Wang, J 2014,“A new MCDM method combining QFD with TOPSIS for knowledge management system selection from the user's perspective in intuitionistic fuzzy environment". Applied soft computing, 21: 28-37.

[9] Mardani,A.,Juosh,A.,Zavadskas,E.K.,Zakuan,N.,Valipour,A.,\&Kazemi lari,M 2014, "Proposing new hierarchical framework for the evaluation of quality management practices: a new combined fuzzy hybrid MCDM approach." Journal of Business Economics and Management,17(1):1-16.

[10] Pavlovskis, M., Antucheviciene, J., \&Migilinskas, D. 2014,Application of MCDM and BIM for Evaluation of Asset Redevelopment Solutions. Studies in Informatics and Control, 25(3) : 293-302.

[11] Ren,J., Manzardo,A.,Mazzi,A.,Zuliani,F.,\&Scipioni,2015, A."Prioritization of bioethanol production pathways in China based on life cycle sustainability assessment and multicriteria decision making". The International Journal of Life cycle Assessment ,20(6) :.842-853

[12] Stevic Z, Vasiljevic M and Veskovic S,2016, Evaluation in logistics using combined AHP and EDAS method, in: XLIII International Symposium on Operational Research, Serbia, : 309-311.

[13] Zavadskas, E.K., Turksis, Z., and Antucheviciene, J . 2015, "Selecting contractor by using a Novel Method for Multiple Attribute Analysis: Weighted Aggregated Sum Product Assessment with Grey values (WASPAS-G)".Studies in Informatics and Control, 24(2):141-150

[14] Zavadskas, E.K., Turksis, Z., Volvaciovas, R., Kidiene, S.2013 "Multicriteria assessment model of technologies". Studies in Informatics and Control, 22(4):.249-258 